Tropical Journal of Pharmaceutical Research September 2021; 20 (9): 1941-1947

ISSN: $1596-5996$ (print); 1596-9827 (electronic)

(C) Pharmacotherapy Group, Faculty of Pharmacy, University of Benin, Benin City, 300001 Nigeria

\title{
Dioscorea deltoidei (Dioscoreaceae) leaf extract exerts anti-atherosclerotic effect in rats via down-regulation of phosphorylated JAK/STAT
}

\author{
Huawei Tian, Yuping Li, Jun Zhang* \\ Department of Cardiology, Xiangyang No.1 People's Hospital, Hubei University of Medicine, Xiangyang, Hubei, China, 441000
}

*For correspondence: Email: t0013140@sina.com; Tel: 0086-0710-3420031

Sent for review: 18 December 2020

Revised accepted: 11 August 2021

\begin{abstract}
Purpose: To investigate the effect of leaf extract of Dioscorea deltoidea (Dioscoreaceae) leaf (DDE) on atherosclerosis-induced aorta wall damage in a rat model, and the underlying mechanism of action. Methods: Rats were fed high-fat diet containing vitamin D2 for 16 weeks to induce atherosclerosis. Histopathological changes in the aorta were examined using hematoxylin and eosin (H \& E) staining, while ELISA kits were used to measure cytokine levels.

Results: Treatment with DDE significantly $(p<0.05)$ alleviated atherosclerosis-induced increase in mean lesion area in the rat aorta. The mean lesion area in atherosclerotic rats was decreased to 51.5, 21.2 and $2.3 \mathrm{~mm} 2$, on treatment with $D D E$ at doses of 2.5, 5 and $10 \mathrm{mg} / \mathrm{kg}$, respectively. Furthermore, $D D E$ significantly suppressed atherosclerosis-induced elevation in IL-1 $\beta$ and IL-6 levels in the rat aorta $(p<0.05)$. The levels of MCP-1 and TNF- $\alpha$ decreased in the artherosclerotic rats on treatment with $D D E$. In DDE-treated rats, the atherosclerosis-induced increase in the levels of Ang II, AT1, AT2, $p$ STAT3, $p-p 65$ and $p$-p38 were significantly decreased, relative to the model group $(p<0.05)$. However, DDE treatment did not alter the levels of total STAT3, $p 65$ and p38 in the rat aorta tissues.

Conclusion: These results indicate that DDE inhibits inflammatory response and atherosclerosisinduced damage to aorta wall. Moreover, RAAS expression, inflammatory cytokines and JAK/STAT signalling pathway were down-regulated in atherosclerotic rats on treatment with DDE. Thus, DDE may be a potential source of drug for the management of atherosclerosis.
\end{abstract}

Keywords: Atherosclerosis, Dioscorea deltoidei, Inflammation, Aorta damage, Angiotensin II

\begin{abstract}
This is an Open Access article that uses a funding model which does not charge readers or their institutions for access and distributed under the terms of the Creative Commons Attribution License (http://creativecommons.org/licenses/by/4.0) and the Budapest Open Access Initiative (http://www.budapestopenaccessinitiative.org/read), which permit unrestricted use, distribution, and reproduction in any medium, provided the original work is properly credited.
\end{abstract}

Tropical Journal of Pharmaceutical Research is indexed by Science Citation Index (SciSearch), Scopus, International Pharmaceutical Abstract, Chemical Abstracts, Embase, Index Copernicus, EBSCO, African Index Medicus, JournalSeek, Journal Citation Reports/Science Edition, Directory of Open Access Journals (DOAJ), African Journal Online, Bioline International, Open-J-Gate and Pharmacy Abstracts

\section{INTRODUCTION}

Atherosclerosis, a common pathological condition, is the leading cause of cerebrovascular and coronary diseases associated with very high morbidity and mortality globally [1]. Atherosclerosis is characterized by formation of fatty streaks and accumulation of atheromatous plaques [2]. The primary method of treatment of atherosclerosis is lifestyle modification, whereas medicines are used for advanced stage of the disease [3]. The most common class of medicines used for the treatment of atherosclerosis are statins [3]. However, the currently-available medicines are ineffective for suppression of atherosclerosis in 
most of the susceptible individuals [4]. This indicates that more effective drugs are required for treating atherosclerosis. Abnormality in metabolism of lipids is considered to be a major factor in induction of atherosclerosis [5]. Individuals with similar cholesterol levels have been found to show discrepancies in the pathogenesis of atherosclerosis [6].

Evidence from various studies have demonstrated the key role of inflammation in the pathogenesis of atherogenesis [5,6]. Initially, it was found that atherosclerosis was associated with levels of macrophages, but later-on, leukocytes were also found to be associated with development of atherosclerotic lesions [7]. Cytokines give rise to chronic inflammation [8]. The signalling molecules associated with inflammation include nuclear factor-kB (NF-KB) and Janus kinase/signal transducers and activators of transcription (JAK/STAT). In addition, the mitogen-activated protein kinase (MAPK) pathway is involved in chronic inflammation [8]. Studies on cytokine-deficient animals have revealed the key role of interleukins and apolipoprotein $E$ in the pathogenesis of atherosclerosis [9]. Indeed, mice deficient in interleukin-1 $\beta$ had reduced atherosclerotic lesions, when compared with mice that expressed interleukin-1 $\beta$ [9].

Cardiovascular risk has been linked to levels of C-reactive protein, TNF- $\alpha$ and IL-6. Atherogenesis is also associated with the expression of renin-angiotensin-aldosterone system (RAAS). The main effector of RAAS is angiotensin II (Angll) and it plays important role as a proinflammatory factor. In an earlier study, an increase in anti-inflammatory effect was observed when the expression of Angll was blocked using ACEls and ARBs [9].

Dioscorea genus belongs to the Dioscoreaceae family which grows at high temperatures in tropical and sub-tropical regions globally. These plants have been used for pharmacological applications as formulations, and for industrial uses [10]. The tubers of several Dioscorea species have been used to treat several diseases/ailments such as cough, cold, stomach ache, leprosy, burns, fungal infections, dysentery, skin diseases, rheumatism and arthritis [10]. Several pharmaceutically important compounds have been isolated from plants of Dioscorea species [11].

In the present study, the effect of leaf extract of Dioscorea deltoidea (DDE) on atherosclerosisinduced aorta wall damage in vivo was investigated in a rat model.

\section{EXPERIMENTAL}

\section{Animals}

Seventy-five male, 12-week-old Sprague Dawley rats weighing 210 - $240 \mathrm{~g}$, were obtained from the Animal Centre of the Binzhou Medical University, China. The rats were kept at ambient temperature $\left(23 \pm 1{ }^{\circ} \mathrm{C}\right)$ under 12-h/12-h light/dark cycle and relative humidity of $62-65 \%$. Standard rodent diet and tap water were made available to the rats ad libitum. The Animal Ethics Committee of the Hubei University of Medicine, China approved all experimental protocols involving animal studies (approval no. EC/2018/02/00254); furthermore, the studies followed international guidelines for animal studies [12]. The rats were randomly assigned to five groups viz: sham, model (atherosclerotic) group, $2.5 \mathrm{DDE}$ group (treated with DDE at a dose of $2.5 \mathrm{mg} / \mathrm{kg}$ ), 5 DDE (treated with DDE at a dose of $5 \mathrm{mg} / \mathrm{kg}$ ), and 10 DDE (given DDE at a dose of $10 \mathrm{mg} / \mathrm{kg}$ ).

\section{Atherosclerosis rat model}

The atherosclerotic rat model was established by feeding the rats with high fat diet containing vitamin D2 for 16 weeks, as described earlier [13]. The high fat diet consisted of normal feed (83.3 \%), chleolate $(0.5 \%)$, cholesterin (3\%), white plantation sugar (5\%), propylthiouracil $(0.2$ $\%)$, and lard (8\%). All rats were injected with vitamin D2 at a dose of $3 \times 10^{5} \mathrm{U} / \mathrm{kg}$ body weight at the beginning of the study. Dioscorea deltoidea leaf extract was given to the treatment groups from 5th week of the study via gastric perfusion.

\section{Histopathological assessment}

After 16 weeks, all rats were fasted for $8 \mathrm{~h}$, after which they were anesthetized using $10 \%$ chloral hydrate solution $(0.3 \mathrm{ml} / 100 \mathrm{~g})$. The rats were sacrificed via decapitation. The aortas were excised and sliced into sections which were used for determination of pathological changes. One portion was processed into histological slides and subsequently stained using oil red dye for demonstration of presence of lipids. Another portion of aorta was fixed in $4 \%$ paraformaldehyde, sliced into thin sections, stained using hematoxylin and eosin (H\&E), and examined under a light microscope.

\section{Enzyme-linked immunosorbent assay (ELISA)}

Inflammatory cytokine levels in the rat aorta tissues were measured using ELISA. Commercially available ELISA kits (R\&D 
Systems, Minneapolis, MN, USA) were used to measure the levels of MCP-1 (MJE00), IL-1 $\beta$ (RLB00), IL-6 (R6000B), and TNF- $\alpha$ (RTA00) in the aorta tissues, in line with the kit protocols.

\section{Immunohistochemical analysis}

Aorta specimens embedded in paraffin were sliced into $3-\mu \mathrm{m}$ cross-sections using a microtome, de-paraffinized, and subsequently rehydrated. Citrate buffer $(0.1 \mathrm{M}$; pH 6.0) was added to the slides, followed by heating for 25 min in a microwave oven. The activities of endogenously generated peroxidases were quenched by treatment with $3 \% \mathrm{H}_{2} \mathrm{O}_{2}$ for $30 \mathrm{~min}$. Sections treated with BSA (2\%) were incubated overnight at $4{ }^{\circ} \mathrm{C}$ with anti-bodies against AT2, Angll and AT1. Thereafter, the slides were incubated with horseradish peroxidaseconjugated secondary antibodies for $50 \mathrm{~min}$. Staining and subsequent counterstaining were performed with diaminobenzidine and Harris hematoxylin, respectively. Semi-quantitative assessment of the expression levels was conducted on 0 - 3 scale.

\section{Western blotting}

Total protein was extracted from aorta tissues via homogenization in RIPA lysis buffer (Beyotime, Haimen China). The lysate was centrifuged at $12,000 \times \mathrm{g}$ for $25 \mathrm{~min}$ at $4{ }^{\circ} \mathrm{C}$, and the protein content of the supernatant was estimated using BCA kits (Beyotime, Haimen China). Equal amounts of protein (50- $\mu \mathrm{g}$ samples) were resolved on $10 \%$ SDS-PAGE, and electrotransferred onto PVDF membranes. The membranes were blocked by incubation with $5 \%$ skim milk/TBST for $1 \mathrm{~h}$. Then, the membranes were incubated overnight at $4{ }^{\circ} \mathrm{C}$ with primary anti-bodies against p65, p-p65, p-STAT3, STAT3, p38 and p-p38 (Santa Cruz Biotechnology, Inc., Santa Cruz, CA, USA). Thereafter, the membranes were washed with PBS and incubated for $1 \mathrm{~h}$ at room temperature with horseradish peroxidase-conjugated secondary antibody. BeyoECL Star (Beyotime Institute of Biotechnology) was used for visualization. Quantification of protein bands was performed using GeneTools software, version 4.1 (Cambridge, UK).

\section{Quantitative polymerase chain reaction (PCR)}

Total RNA was isolated from aorta tissues using Ultrapure RNA kit. The RNA was reversetranscribed to cDNA, followed by quantitativePCR reaction using $\mathrm{ABI}-7900$ System (Applied Biosystems, Inc.) and SYBR Green (Applied Biosystems, Inc.). The conditions used for amplification were: $94{ }^{\circ} \mathrm{C}$ for $8 \mathrm{~min}$, then 48 cycles at $94{ }^{\circ} \mathrm{C}$ for $25 \mathrm{sec}$, followed by $58{ }^{\circ} \mathrm{C}$ for $20 \mathrm{sec}$. The mRNA levels were quantified for each gene, followed by calculation of relative expressions using the $2-\Delta \Delta \mathrm{Ct}$ method. The primer sequences used are shown in Table 1.

\section{Statistical analysis}

Data are expressed as mean \pm standard deviation (SD). Comparisons were done using one-way analysis of variance (ANOVA) and Bonferroni multiple comparison test. The GraphPad Prism 6 (GraphPad Software, La Jolla, CA) was used for all statistical analyses. Differences were taken as statistically significant at $p<0.05$.

\section{RESULTS}

\section{DDE inhibited atherosclerosis}

There was significant increase in average lesion area in DDE-treated rat group, when compared to the sham group $(p<0.05)$. As shown in Table 2 , the average lesion area in the model atherosclerosis rats increased to $65.3 \mathrm{~mm}^{2}$, relative to $1.8 \mathrm{~mm}^{2}$ in the sham group. However, treatment with DDE led to significant reduction in atherosclerosis-induced increase in average lesion area in the rat aortas $(p<0.05)$. The average lesion area in atherosclerotic rats was decreased to $51.5,21.2$ and $2.3 \mathrm{~mm}^{2}$, on treatment with DDE at doses of $2.5,5$ and 10 $\mathrm{mg} / \mathrm{kg}$, respectively.

Table 1: Sequences of primers used for RT-PCR

\begin{tabular}{lll}
\hline Gene & Forward primer (5'-3') & Reverse primer (5'-3') \\
\hline AT1 & GCAGCACTTCACTACCAAATGG GC & CAGGACAAAAGCAGGCTAGGGAG A \\
Angll & CCGCATTTAACTGCTCACACA & ATCATGTAGTAGAGAACAGGAATT GCTT \\
AT2 & GGAAGGTAGAACATACATTAAA TG & AGAGAAACAGCAGCTAAAGAATT \\
GAPDH & GAGTCAACGGATTTGGTCGT & TTGATTTTGGAGGGATCTCG \\
\hline
\end{tabular}


Table 2: Effect of DDE on lesion areas in atherosclerosis rat model.

\begin{tabular}{lll}
\hline Group & $\begin{array}{l}\text { Atherosclerotic } \\
\text { area }\left(\mathbf{m m}^{2}\right)\end{array}$ & $\begin{array}{l}\text { Lipidoses area } \\
\left(\mathbf{m m}^{2}\right)\end{array}$ \\
\hline Sham & $1.8 \pm 0.54$ & $0.93 \pm 0.32$ \\
Model & $65.3 \pm 5.43$ & $45.5 \pm 4.76$ \\
$2.5 \mathrm{mg} / \mathrm{kg}$ & $51.5 \pm 5.27$ & $34.6 \pm 4.11$ \\
$5 \mathrm{mg} / \mathrm{kg}$ & $21.2 \pm 3.87$ & $12.9 \pm 2.32$ \\
$10 \mathrm{mg} / \mathrm{kg}$ & $2.3 \pm 0.42$ & $1.8 \pm 0.26$ \\
\hline
\end{tabular}

\section{DDE down-regulated atherosclerosis- induced inflammatory cytokines}

Atherosclerosis induction caused significant increases in levels of IL- $1 \beta$ and IL- 6 in rat aorta tissues, relative to the sham group $((p<0.05$; Figure 1). Moreover, atherosclerosis increased the expression levels of MCP-1 and TNF- $\alpha$ in the rat aorta tissues. However, treatment with DDE at doses of $2.5,5$ and $10 \mathrm{mg} / \mathrm{kg}$ significantly suppressed the atherosclerosis-induced upregulation in expression levels of IL-1 $\beta$ and IL- 6 in the rat aortas. Moreover, the expression levels of MCP-1 and TNF- $\alpha$ in rats with atherosclerosis were reduced on treatment with DDE.

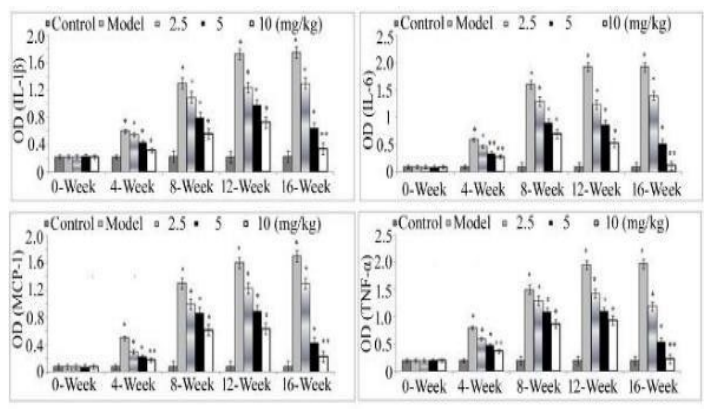

Figure 1: Effect of DDE on inflammatory cytokine levels. After induction of atherosclerosis, the rats were treated with DDE at doses of $2.5,5$ and $10 \mathrm{mg} / \mathrm{kg}$. ELISA was used for determination of cytokine levels in the rat aortas. ${ }^{*} P<0.05,{ }^{* *} p<0.02$, compared to sham group

\section{DDE decreased activation of athero- sclerosis-induced RAAS}

Atherosclerosis increased the expression levels of Angll, AT1 and AT2 in rat aorta tissues, when compared to the control group (Figure 2). However, treatment of the rats with DDE led to marked reversal of the atherosclerosis-induced increases in levels of Angll, AT1 as well as AT2 $(p<0.05)$. The reductions in levels of Angll, AT1 and AT2 were maximum in rats treated with DDE at a dose of $10 \mathrm{mg} / \mathrm{kg}$.

Results from RT-PCR showed that atherosclerosis caused increases in mRNA expression levels of Angll, AT1 and AT2 in the rat aorta tissues, when compared to the control group. However, DDE treatment significantly reversed atherosclerosis-induced increases in mRNA levels of Angll, AT1 and AT2. The results showed that DDE was most effective at the dose of $5 \mathrm{mg} / \mathrm{kg}$.

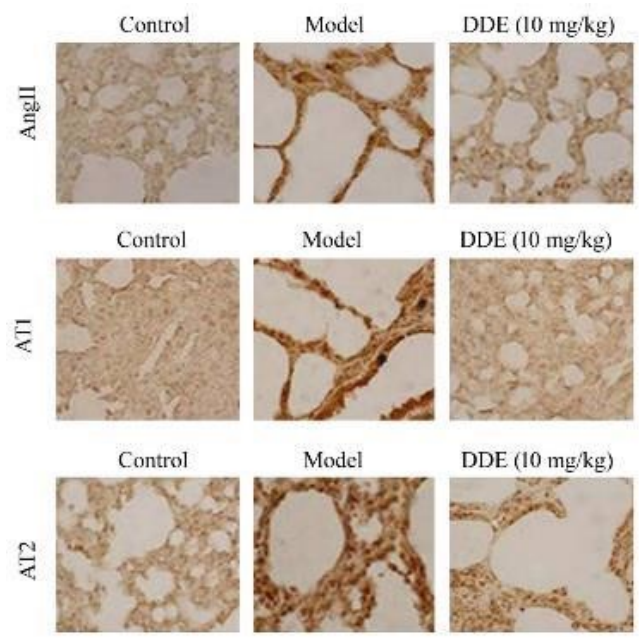

Figure 2: Effect of DDE on RAAS activation. After induction of atherosclerosis, the rats were treated with DDE at doses of $2.5,5$ and $10 \mathrm{mg} / \mathrm{kg}$. The mRNA levels of RAAS family members in the rat aortas were determined using immunohistochemical staining

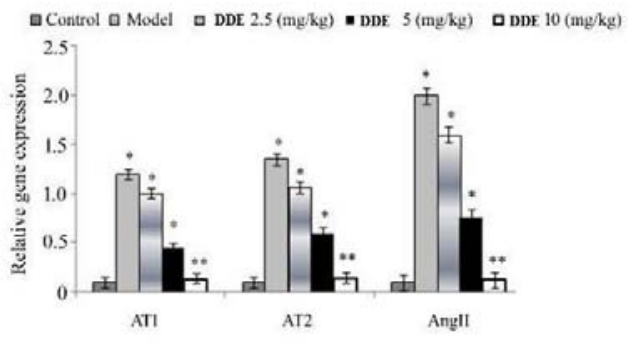

Figure 3: Effect of DDE on levels of RAAS members. After induction of atherosclerosis, the rats were treated with DDE at doses of $2.5,5$ and $10 \mathrm{mg} / \mathrm{kg}$, followed by determination of mRNA expression levels of Angll, AT1 and AT2 mRNA. ${ }^{*} P<0.05,{ }^{* *} p<0.02$, compared to sham group

\section{DDE alleviated atherosclerosis-induced inflammatory pathways}

Atherosclerosis induction in rats led to upregulated expression levels of p-STAT3, p-p65 and p-p38 in aorta tissues, when compared to the control group (Figure 4). However, atherosclerosis had no impact on the expression levels of total STAT3, p65 and p38 in the rat aorta tissues. Treatment with DDE caused marked suppression of atherosclerosis-induced increases in levels of p-STAT3, p-p65 and p-p38, when compared to the model group. The atherosclerosis-induced elevations in p-STAT3, 
p-p65 and p-p38 were suppressed to minimum levels in rats treated with DDE at a dose of 10 $\mathrm{mg} / \mathrm{kg}$.

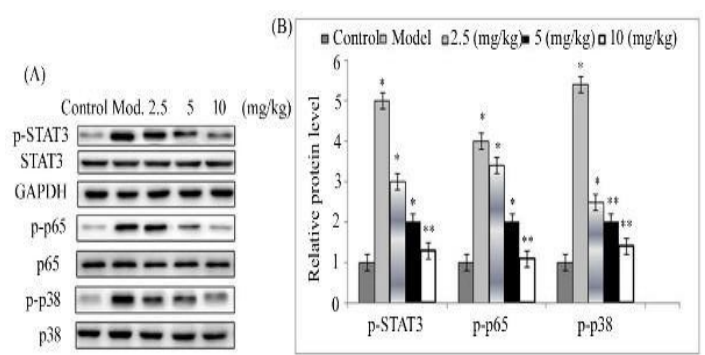

Figure 4: Effect of DDE on expressions of inflammatory pathway-associated proteins. (A) Changes in expression levels of p-STAT3, p-p65 and p-p38 in the aorta tissues of atherosclerotic rats, as determined using Westing blot assay. (B) Quantified protein bands, with GAPDH as standard. ${ }^{*} P<0.05$, ${ }^{* *} p<0.02$, compared to sham group

\section{DISCUSSION}

Continuous administration of high-fat diet initiates a series of events in rat aortas which include elevated cytokine production, recruitment of immune cells and structural damage to the wall of aorta [14]. The histological features induced by these events in the aorta have close resemblance to those of atherosclerosis in humans. Chronic inflammation is associated with the pathogenesis of atherosclerosis. The initial stage of atherosclerosis is characterised by excess generation of pro-inflammatory cytokines in cardiovascular cells [15].

Endothelial as well as vascular muscle cells are cardiovascular cells that produce high levels of IL-1 $\beta$, IL-6, MCP-1 and TNF- $\alpha$ during chronic inflammation [15]. Several other cardiovascular cells are activated by these cytokines, leading to disturbance in homeostasis and activation of inflammatory response in the aorta wall. It has been reported that suppression of inflammatory response in animal models leads to inhibition of atherosclerosis [16]. In the present study, atherosclerosis led to a significant increase in average lesion area in the rat aortas. However, the average lesion area was significantly lowered in aortas of the atherosclerotic rats on treatment with DDE. This indicates that DDE inhibited atherosclerosis-induced aorta wall damage in rats.

The levels of IL-1 $\beta, I L-6, M C P-1$ and TNF- $\alpha$ in aorta tissues of the atherosclerotic rats were significantly increased, when compared to sham group. In DDE-treated rats, the atherosclerosisinduced elevations in levels of IL-1 $\beta$ and IL-6 were significantly reversed, when compared to the model group. Treatment with DDE also reversed atherosclerosis-mediated upregulation of MCP-1 and TNF- $\alpha$ levels in rat aortas. These findings indicate that DDE alleviated the aorta damage due to atherosclerosis-induced inflammatory response in the rats.

It has been established that RAAS plays a key role in activation of vascular damage induced by inflammatory response which leads to formation of fatty streaks and foam cells, followed by rupture of the vulnerable plaques [17]. The reninangiotensin-aldosterone system is also associated with maintenance of sodium balance and volume of the extracellular fluids. Many RAAS antagonists such as ACEls and ARBs have been shown to inhibit inflammatory processes in vivo [18]. In the present study, atherosclerosis increased the levels of Angll, AT1 and AT2 in rat aortas. However, DDE treatment led to marked reversal of the atherosclerosis-induced increases in levels Angll, AT1 and AT2.

The NF-kB pathway regulates several inflammatory responses, and is also associated with the progression of atherosclerosis [19]. The deactivation of NF-KB via endothelium restriction has been demonstrated to suppress the formation of atherosclerotic plaques [20]. Moreover, it has been reported that the JAK/STAT pathway is involved in the pathogenesis of atherosclerosis [21]. Activated JAK/STAT is present in atherosclerotic lesions [22]. Incubation of vascular cells with Angll or cytokines has been shown to activate the JAK/STAT pathway [23]. In the present study, atherosclerosis significantly enhanced the expression of p-p65 in the aortas of the rats. Moreover, the expression levels of p-STAT3 and p-p38 were up-regulated in atherosclerotic rats, when compared to the sham group. However, treatment with DDE led to down-regulation of the expressions of p-STAT3, p-p65 and p-p38 in the aorta tissues of the atherosclerotic rats.

\section{CONCLUSION}

These results indicate that DDE protects rats from atherosclerosis-induced damage to aorta wall and inflammatory response. Moreover, RAAS expression, inflammatory cytokines and JAK/STAT signalling pathway are downregulated in atherosclerotic rats on treatment with DDE. Thus, DDE is a potential remedy for the treatment of atherosclerosis in humans.

Trop J Pharm Res, September 2021; 20(9): 1945 


\section{DECLARATIONS}

\section{Conflict of interest}

No conflict of interest is associated with this work.

\section{Contribution of authors}

We declare that this work was done by the authors named in this manuscript and all liabilities pertaining to claims relating to the content of this manuscript will be borne by the authors. Huawei Tian and Yuping Li contributed to this work equally. Huawei Tian and Yuping Li performed the experimental work, carried out the literature survey, and analysed and compiled the data. Jun Zhang designed the study and wrote the manuscript. All the authors read the paper and approved it for publication.

\section{Open Access}

This is an Open Access article that uses a funding model which does not charge readers or their institutions for access and distributed under the terms of the Creative Commons Attribution License (http://creativecommons.org/licenses/by/ 4.0) and the Budapest Open Access Initiative (http://www.budapestopenaccessinitiative.org/rea d), which permit unrestricted use, distribution, and reproduction in any medium, provided the original work is properly credited.

\section{REFERENCES}

1. Roger VL, Go AS, Lloyd Jones DM, Benjamin EJ, Berry $J D$, Borden WB, Bravata DM, Dai S, Ford ES, Fox CS, Fullerton HJ, et al. American Heart Association Statistics Committee and Stroke Statistics Subcommittee: Heart disease and stroke statistics 2012 update: a report from the American Heart Association. Circulation 2012; 125: e2 e220.

2. Weber C, Zernecke A, Libby $P$. The multifaceted contributions of leukocyte subsets to atherosclerosis: lessons from mouse models. Nat Rev Immunol 2008; 8: 802815.

3. Koh KK. Combination treatment to prevent atherosclerosis. Hypertension 2009; 54: e10 e11.

4. Tian J, Gu X, Sun Y, Ban X, Xiao Y, Hu S, Yu B. Effect of statin therapy on the progression of coronary atherosclerosis. BMC Cardiovasc Disord 2012; 12: 70.

5. Ross R, Harker L. Hyperlipidemia and atherosclerosis. Sci 1976; 193: 10941100.

6. Inadera H, Hamazaki T. Cholesterol controversy: cutoff point of low-density lipoprotein cholesterol level in Guidelines by Japan Atherosclerosis Society. Nihon Eiseigaku Zasshi 2010; 65: 506515 (In Japanese).
7. Gerszten RE, Mach F, Sauty A, Rosenzweig A, Luster $A D$. Chemokines, leukocytes, and atherosclerosis. J Lab Clin Med 2000; 136: 8792

8. Frieri M. Accelerated atherosclerosis in systemic lupus erythematosus: role of proinflammatory cytokines and therapeutic approaches. Curr Allergy Asthma Rep 2012; 12: 2532.

9. Morris JB, Olzinski AR, Bernard RE, Aravindhan K, Mirabile RC, Boyce R, Willette RN, Jucker BM. p38 MAPK inhibition reduces aortic ultrasmall superparamagnetic iron oxide uptake in a mouse model of atherosclerosis: MRI assessment. Arterioscler Thromb Vasc Biol 2008; 28: 265271.

10. Zaritsky JJ, Kalantar Zadeh K. The crossroad of RAAS modulation, inflammation, and oxidative stress in dialysis patients: light at the end of the tunnel? J Am Soc Nephrol 2012; 23: 189191.

11. Kumar S, Das G, Shin HS, Patra JK. Dioscorea spp. (a wild edible tuber): a study on its ethnopharmacological potential and traditional use by the local people of Similipal Biosphere Reserve, India. Front. Pharmacol. 2017; 8: 52.

12. Festing $S$, Wilkinson R. The ethics of animal research. Talking Point on the use of animals in scientific research. EMBO Rep. 2007; 8: 526-530.

13. Zhou BR, Pan $Y$, Zhai ZM. Fibrinogen and $P$ selectin expression in atherosclerosis model of Sprague Dawley rat. Chin Med J (Engl) 2011; 124: 37683772.

14. Fotis L, Agrogiannis G, Vlachos IS, Pantopoulou A, Margoni A, Kostaki M, Verikokos C, Tzivras $D$, Mikhailidis DP, Perrea $D$. Intercellular adhesion molecule (ICAM) 1 and vascular cell adhesion molecule (VCAM) 1 at the early stages of atherosclerosis in a rat model. In Vivo 2012; 26: 243250.

15. Fan J, Watanabe $T$. Inflammatory reactions in the pathogenesis of atherosclerosis. J Atheroscler Thromb 2003; 10: 6371.

16. Paoletti R, Gotto AM Jr, Hajjar DP. Inflammation in atherosclerosis and implications for therapy. Circulation 2004; 109 (23 Suppl 1): III20 III26.

17. Fukui K, Yamada H, Matsubara H. Pathophysiological role of tissue renin angiotensin aldosterone system (RAAS) in human atherosclerosis. Nihon Rinsho 2012; 70: 15561561 (In Japanese).

18. Fukuda $D$, Enomoto $S$, Nagai $R$, Sata M. Inhibition of renin angiotensin system attenuates periadventitial inflammation and reduces atherosclerotic lesion formation. Biomed Pharmacother 2009; 63: 754761.

19. Monaco C, Andreakos E, Kiriakidis S, Mauri C, Bicknell C, Foxwell B, Cheshire N, Paleolog E, Feldmann M. Canonical pathway of nuclear factor kappa $B$ activation selectively regulates proinflammatory and prothrombotic responses in human athero-sclerosis. Proc Natl Acad Sci USA 2004; 101: 56345639.

20. Gareus R, Kotsaki E, Xanthoulea S, Van der Made I, Gijbels MJJ, Kardakaris R, Polykratis A, Kollias G, de Winther MPJ, Pasparakis M. Endothelial cell specific NF

Trop J Pharm Res, September 2021; 20(9): 1946 
kappaB inhibition protects mice from atherosclerosis. Cell Metab 2008; 8: 372383.

21. Ortiz Muñoz G, Martin Ventura JL, Hernandez Vargas $P$, Mallavia B, Lopez-Parra V, Lopez-Franco O, MuñozGarcia B, Fernandez-Vizarra $P$, Ortega L, Egido J, Gomez-Guerrero C. Suppressors of cytokine signaling modulate JAK/STAT mediated cell responses during atherosclerosis. Arterioscler Thromb Vasc Biol 2009; 29: 525531.
22. Gharavi NM, Alva JA, Mouillesseaux KP, Lai C, Yeh M, Yeung $W$, Johnson J, Szeto $W L$, Hong L, Fishbein $M$, Wei L, Pfeffer LM, Berliner JA. Role of the Jak/STAT pathway in the regulation of interleukin 8 transcription by oxidized phospholipids in vitro and in atherosclerosis in vivo. J Biol Chem 2007; 282: 3146031468.

23. O'Sullivan LA, Liongue $C$, Lewis RS, Stephenson SE, Ward AC. Cytokine receptor signaling through the Jak Stat Socs pathway in disease. Mol Immunol 2007; 44: 24972506. 